Revue musicale OICRM

\title{
Chanter l'athlète moderne, entre ridiculisation et glorification
}

Federico Lazzaro

Volume 4, numéro 2, 2017

Enjeux culturels dans la presse musicale française, 1900-1925

URI : https://id.erudit.org/iderudit/1043221ar

DOI : https://doi.org/10.7202/1043221ar

Aller au sommaire du numéro

Éditeur(s)

Observatoire interdisciplinaire de création et recherche en musique (OICRM)

ISSN

2368-7061 (numérique)

Découvrir la revue

Citer cet article

Lazzaro, F. (2017). Chanter l'athlète moderne, entre ridiculisation et glorification. Revue musicale OICRM, 4(2), 75-98.

https://doi.org/10.7202/1043221ar
Résumé de l'article

En 1922, le quotidien culturel Comoedia lance le concours de musique, de poésie et d'architecture " L'art et le sport », " pour glorifier l'athlète moderne ". La pièce musicale gagnante, Cortège d'athlètes de Louis Vuillemin, est une oeuvre ouvertement militaire et nationaliste. Cet article retrace les liens entre la gymnastique, le sport et la musique en France entre 1870 le début des années 1920 afin de comprendre les origines et les raisons de la militarisation de la musique à sujet sportif. 


\title{
Chanter l'athlète moderne, entre ridiculisation et glorification
}

Federico Lazzaro

\begin{abstract}
Résumé
En 1922, le quotidien culturel Comoedia lance le concours de musique, de poésie et d'architecture "L'art et le sport ", " pour glorifier l'athlète moderne ». La pièce musicale gagnante, Cortège d'athlètes de Louis Vuillemin, est une œuvre ouvertement militaire et nationaliste. Cet article retrace les liens entre la gymnastique, le sport et la musique en France entre 1870 le début des années 1920 afin de comprendre les origines et les raisons de la militarisation de la musique à sujet sportif.

Mots clés : sport ; France ; Troisième République ; chanson ; musique militaire.

Abstract

In 1922, the daily cultural journal Comoedia launches the competition "Art and Sport", which asks musicians, poets and architects to "glorify the modern athlete". The winning musical piece, Cortège d'athlètes by Louis Vuillemin, is an overtly military and nationalistic work. This article traces out the relationship between gymnastics, sport and music in France from 1870 to the beginning of the 1920s, in order to understand how and why a military music connected to sport came about.
\end{abstract}

Keywords: sport; France; Third Republic; song; military music.

La bêtise de l'opérette, du marbre, du chic, du sport peuvent bien se fondre et former un tout. [...] Ces ensembles ont toujours un côté militaire (Cocteau [1924]2003, p. 57).

Cet article s'inscrit dans un projet de recherche sur la musique et le sport en France sous la Troisième République, un parcours d'histoire culturelle du musical et d'histoire musicale du culturel qui vise à étudier les façons dont la musique interagit avec les différentes valeurs associées au sport (préparation militaire, divertissement de masse, compétition internationale, exaltation de l'homme-machine et de la vitesse, etc.) à une époque où celui-ci prend une place de plus en plus importante dans la société ${ }^{1}$.

1 Dans cet article nous reprenons, approfondissons et intégrons les propos présentés lors de conférences et communications (Lazzaro 2014a, 2014b et 2015-2016). Si, dans ces précédentes contributions, 
La musique peut accompagner l'activité sportive, l'entourer, la commenter ou encore s'en inspirer. Dans une précédente contribution (Lazzaro 2014b), nous avons étudié les enjeux esthétiques relatifs aux différentes modalités de relation entre la musique et le sport en nous penchant sur l'enquête " La musique et le sport " publiée par Le Guide du concert à la suite des Jeux olympiques de Paris en 1924 ; dans une analyse parue récemment (Lazzaro 2017), nous nous sommes concentré plus particulièrement sur le sport comme source d'inspiration musicale, en explorant l'idée de " son du sport » qui caractériserait l'orchestration des poèmes symphoniques à sujet sportif composés dans les années 1920. Le présent article aborde plutôt les champs constitués par la musique qui entoure les compétitions sportives et par celle qui offre un commentaire à propos de l'engouement sportif. Plus spécifiquement, nous nous concentrons sur la musique chantée (chansons et hymnes) et sur deux manières de " chanter » l'athlète : sa ridiculisation (une attitude très présente, dès le tournant du siècle, dans le répertoire des chansons de café-concert) et, au contraire, sa glorification. Cette dernière, qui s'affirme après la Première Guerre mondiale, est au cour de la problématique qui a guidé notre démarche : quels sont les liens entre la musique écrite pour les compétitions sportives des années de l'esprit pacifiste d'après-guerre (qui se traduit notamment dans l'idéal d'une paix durable entre les nations représenté par la constitution, dès 1919, de la Société des Nations) et la musique militaire? La musique sportive serait-elle l'adaptation pacifiste de la musique militaire, au même titre que héros-athlète qui serait l'adaptation pacifiste du héros-guerrier ? Si les questions des liens entre activité physique et préparation à la guerre ou des compétitions sportives comme forme substitutive de la guerre ont été étudiées par plusieurs historiens ${ }^{2}$, le phénomène musical n'a que très rarement été pris en considération, et jamais dans le cas de la France ${ }^{3}$. Cet article se veut une première étape de ce parcours de recherche ; il se base principalement sur le corpus de partitions à sujet sportif conservées au Département de la musique de la Bibliothèque nationale de France $(\mathrm{BnF})$ et a pour élément déclencheur le concours « L'art et les sports » lancé par Comodia en 1922.

nous avions insisté sur la dichotomie entre gymnastique (subventionnée par l'État et liée à la préparation militaire) et sport (privé et associé au loisir), nous préférons ici l'atténuer en faveur d'une utilisation élargie du mot «sport » pour indiquer tout le spectre du continuum de l'activité physique - de la préparation militaire au pur loisir -, car cela nous semble plus pertinent pour une analyse des rapports entre toute activité physique confondue et musique. Cette dernière peut en effet traverser les bornes entre les différentes disciplines gymniques, athlétiques et sportives et leurs connotations et fonctions respectives dans la société française de la Troisième République. Pour une mise en récit du parcours chronologique entre les deux pôles du continuum gymnastique/sport, nous renvoyons au classique Ulmann 1977.

2 La problématique du rapport entre le sport et la guerre est au centre de l'« histoire des pratiques corporelles » écrite par Nicolas Bancel et Jean-Marc Gayman (2002), intitulé significativement Du guerrier à l'athlète, ainsi que du collectif dirigé par Luc Robène (2012a), auteur également de l'article « Guerre » du Dictionnaire culturel du sport (Attali et Saint-Martin 2010). En ce qui concerne plus spécifiquement le cas de la France, voir aussi les articles de Paul Dietschy, Jacques Defrance et Jean Saint-Martin dans l'Histoire du sport en France dirigée par Philippe Tétart (2007).

3 La seule exception étant un article sur le chant scolaire par Thierry Terret (1997). Pour des exemples hors France du même phénomène de rapprochement entre musique de guerre et musique sportive dans les années 1920, voir Hill 2009 et Nannestad 2015. Il est révélateur que, lors du colloque L'art et le sport de 2007 (Daniel 2009), il n'ait été question de musique dans aucune communication. 
UN CONCOURS « POUR GLORIFIER L’ATHLÈTE MODERNE »

En février 1922, la revue Comodia ouvre le concours "L'art et les sports ", un concours de sculpture, de musique et de poésie " pour glorifier l'athlète moderne " (Comodia 1922 ; René-Jean 1922 ; Charpentier 1922 ; Valmy-Baysse 1922).Ce concours est lancé à la demande d'Adolphe Chéron, député et président de l'Union des sociétés d'éducation physique et de préparation au service militaire, en lien avec l'inauguration d'un " stade modèle » au Parc de Saint-Maur, dans le département du Val-de-Marne (Chéron 1922) ${ }^{4}$, une initiative en ligne avec l'intégration des infrastructures sportives dans le développement urbain promue, dans un but hygiéniste, par la loi Cornudet de mars 1919 (Clastres et Dietschy 2006, p. 104-105 ; Callède 2000 et 2007).

Dans ce contexte de nouvelles politiques publiques en faveur du sport conçu comme facteur d'hygiène sociale, Chéron a lancé le concours dans le cadre d'une campagne pour la création de nouveaux stades, un souci d'hygiène pour les grandes villes qui devraient " prévoir des espaces libres nécessaires à la santé de leurs habitants » (Chéron 1922). C'est un projet de société qui englobe à la fois l'imaginaire du héros grec, l'hygiénisme sportif de masse et le nationalisme féroce que la guerre a contribué à répandre et durcir" ${ }^{5}$ L'appel de Chéron aux artistes pour qu'ils " glorifient l'athlète moderne » se fait en effet sur des tons machistes et nationalistes :

[Aux compositeurs :] Musiciens, par la composition d'un Cortège d'athlètes, tour à tour solennel, alerte, triomphal, retrouvez les harmonies dont les doigts fins des jeunes filles, sous le ciel bleu de l'Attique, faisaient vibrer les lyres des Panathénées.

[Aux poètes :] Magnifie[z] le corps humain, [...] vantez la forme féminine rayonnante des espoirs de la fécondité ; exprimez la joie de perpétuer l'espèce en créant des êtres sains, forts et beaux, [...] chantez le relèvement de la Patrie par l'épanouissement de la race en beauté comme en nombre.

[Aux sculpteurs :] Fixez d'une main robuste dans un Athlète saluant le « canon » capable de perpétuer devant les âges à venir la renaissance de la France victorieuse (Chéron 1922).

Le texte de l'appel du concours de musique, signé Raymond Charpentier (qui était à l'époque le rédacteur en chef de Comoedia, en plus d'être directeur de la musique à la Comédie française) demande explicitement que

la musique du Cortège d'athlètes [reste] dans le genre populaire. Nulle fête de l'athlétisme ne saurait se concevoir sans un grand concours du peuple. Il est naturel qu'il faille rechercher, dans l'œuvre musicale destinée à scander et à souligner le

$4 \quad$ Le stade a été inauguré le 28 mai 1922 et en 1952 sera baptisé Stade Adolphe-Chéron (Clavel 2014, p. 147). C'est à Saint-Maur que l'École normale de gymnastique de Joinville a recommencé ses activités après la guerre, en 1919.

5 Parmi les acteurs de l'hygiénisme sportif nationaliste (« développer la santé, améliorer la race, servir la patrie ", Saint-Martin 2006, p. 122), on pourrait évoquer ici Philippe Tissié (1852-1935), qui publie, en 1919, L'éducation physique et la race : santé, travail, longévité, dédié aux Poilus de la Grande Guerre (voir Saint-Martin 2006). 
défilé des athlètes sous les regards de la foule, les accents propres à émouvoir l'âme collective "(Charpentier 1922, p. 1).

Cet appel au « populaire »-dans lequel on pourrait voir une conception patriotique de type révolutionnaire plutôt que nationaliste - est expliqué davantage. Les organisateurs du concours mettent en garde contre " un certain genre de "musique populaire" (ou soi-disant telle) conçu uniquement sous l'angle commercial» (ibid.). Au contraire, la musique du Cortège d'athlètes - qui « devra être conçue pour être exécutée en plein air par une ou plusieurs musiques d'harmonie ou fanfare » (ibid., p. 2) - devra être " d'une exécution relativement facile, d'un style élevé et populaire " (ibid.). Cette requête trouve une explication raciale et nationaliste : «si [...] l'athlète parfait doit incarner les traits dominants et la beauté caractéristique de sa race, on peut penser que la marche composée à la gloire de l'athlète synthétisera les admirations et les goûts sportifs de cette race " (ibid., p. 1). Il est sans doute significatif, à ce propos, qu'il soit demandé aux compositeurs qui participent au concours d'inclure dans l'enveloppe « la justification de [leur] qualité de Français » (ibid., p. 2). Il est évident que l'athlète-héros que ce concours veut célébrer est le substitut du guerrier-héros exalté pendant et tout de suite après la Guerre ${ }^{6}$. La France a besoin de nouveaux héros qui représentent la force de la nation dans une phase historique visant une paix durable. Dans les faits, l'athlète est une figure très ambiguë, à la fois ambassadeur de la paix et incarnant la force de frappe de la nation. Comme le remarque Luc Robène (2012b), le sport constitue alors une troisième voie entre la guerre et la paix totale (p. 9) ${ }^{7}$. Dans la démarche consistant à appréhender le sport « comme objet culturel façonné au creuset de la guerre » (ibid., p. 14), la musicologie peut offrir une contribution importante en étudiant la manière dont la musique participe (avec l'art en général) de la mobilisation symbolique des « fêtes du stade ${ }^{8}$ » en proposant un rite qui pourrait être défini comme « postmilitaire ».

\section{Gymnastique pour guerriers}

Le lien entre éducation physique et service militaire remonte, en France, aux années 1830 et s'institutionnalise, en 1852, avec la création de l'École normale de gymnastique de Joinville. Durant les deux premières décennies de la Troisième République, l'association du " gymnaste et [du] militaire " est forte ${ }^{9}$, et se traduit très pratiquement par le financement étatique de la gymnastique dont le but est de créer des hommes aptes à défendre la nation ${ }^{10}$ ainsi que par des défilés civils où le gymnaste

$6 \quad$ Il ne faut toutefois pas oublier que, comme l'a amplement montré Antoine Prost (1977; [1977]2014 ; [1984]1997), la célébration des morts au lendemain de la guerre était souvent profondément antimilitariste.

7 Robène l'affirme pour la période de la Guerre froide, mais en vérité le sport joue son rôle dès la fin de la Première Guerre mondiale.

8 Voir à ce propos Robène 2012b, p. 13 et n. 37. La référence est à Chambat 1986.

9 Voir les propos de Léon Gambetta cités dans Clastres et Dietschy 2006, p. 44 : « Il faut mettre partout, à côté de l'instituteur, le gymnaste et le militaire ». Sur le rôle idéologique de l'activité physique durant la Troisième République, voir Caillat 1989, Arnaud 1997a, Andrieu 1999 et 2012.

10 1873, naissance de 1'Union des sociétés de gymnastique de France (USGF), subventionnée par 
" est bel et bien un homme nouveau républicain [...] suggér[ant] la régénération de la race et la défense du pays » (Clastres et Dietschy 2006, p. 45) ${ }^{11}$. Comme l'expliquent Pierre Arnaud et James Riordan

les sociétés de gymnastiques sont alors les instruments pédagogiques et politiques de la construction d'une identité nationale. Apprendre à se servir de son corps au service de la patrie relève d'une stratégie d'acculturation et de nationalisation des masses au même titre que l'apprentissage de la langue et de la culture nationale (Arnaud et Riordan 1998, p. 13).

À cette époque et avant le début très tardif des compétitions entre équipes nationales de gymnastes ${ }^{12}$, la gymnastique avait surtout un but de " patriotisme interne »" donner le sentiment d'appartenir à une même nation » (ibid.). Les rencontres entre sociétés de gymnastiques organisées par l'Union des sociétés de gymnastique de France (USGF) offrent déjà, au début de la Troisième République, un cadre symbolique où les corps athlétiques sont « exposés » et véhiculent les valeurs d'ordre et d'excellence collective. La musique, non moins que les drapeaux et les devises, joue un rôle dans cette " utopie pédagogique »(Chambat 1997, p. 260). Les symboles fusionnent, en renforçant les liens entre les différentes composantes du rituel. Par exemple, sur la couverture de la Marche des athlètes par Georges Guerin (1898), figure la devise de 1'Union des sociétés françaises de sports athlétiques (USFSA), "ludus pro patria » (figure 1), tandis que deux drapeaux tricolores complètent la nature morte d'haltères, trapèzes, anneaux et massues sur la couverture de la Marche des sociétés de gymnastique par Daniel Dugenne (1883) (figure 2). Le militarisme associé à l'éducation physique pénètre la musique, donnant lieu à des marches du sport ou des athlètes comme celles listées ci-dessous :

- [1893] : Rungs, Marche du sport, athlétique du lycée de Poitiers, pour piano à quatre mains (Poitiers, Jarasson);

- 1898 : Georges Guerin, Marche des athlètes, «à l'Union des sociétés françaises de sports athlétiques », orchestrée par Gustave Goublier (Paris, L. Coutarel/ La lyre musicale);

- [1903] : L. J. de Schepper, Marche des athlètes, pour harmonie ou fanfare (Paris, E. Van de Valde);

- 1905 : Hippolyte Maquet, Sport-March, pour orchestre (Paris, F. Andrieu) ;

- 1907 : Paul Bades, Marche des athlètes, pour orchestre (Paris, E. Costil).

le gouvernement (voir Arnaud et Riordan 1998, p. 34), dont la devise est " courage, patrie, moralité » (Froissart 2010, p. 64). En revanche, l'Union des sociétés françaises de sports athlétiques (USFSA), née en 1889, est privée, sur le modèle amateur anglais de pratique sportive (voir Turcot 2016, p. 456-466).

11 Sur la place occupée par le sport dans les fêtes républicaines, voir Chambat 1986, Chambat 1997 et Dalisson 2009.

12 La Fédération internationale de gymnastique n'est créée qu'en 1921 (Arnaud et Riordan 1998, p. 13). 


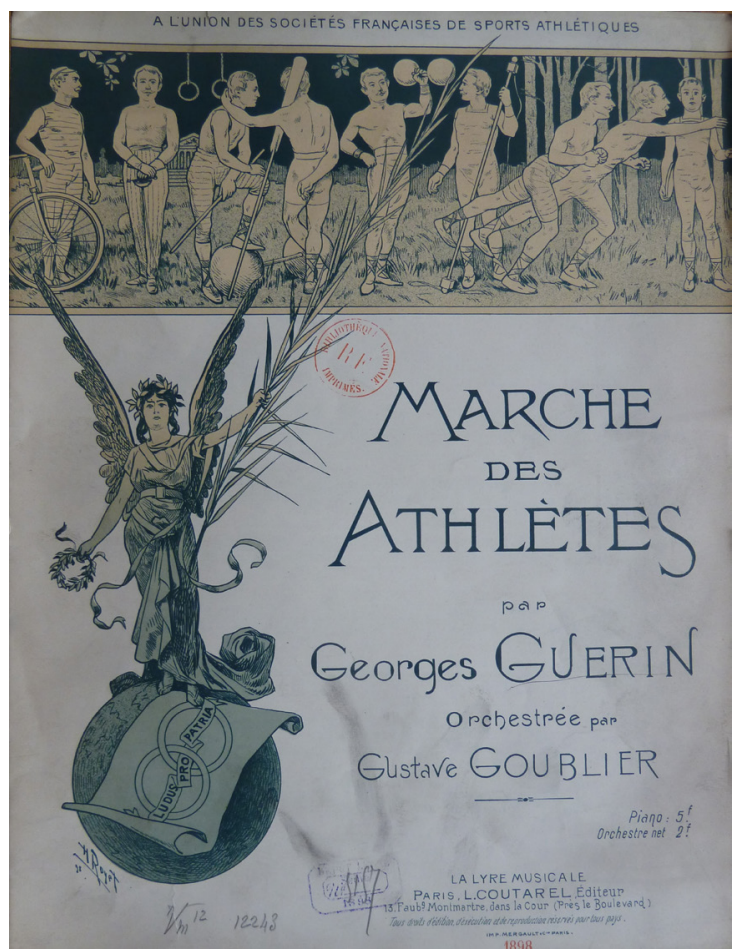

Figure $1: H$. Royet, couverture de la Marche des athlètes de Georges Guerin (Paris, L. Coutarel/La lyre musicale, 1898), avec la devise "ludus pro patria ». Source: BnF.

Figure 2: Anonyme, couverture de la Marche des sociétés de gymnastique de Daniel Dugenne (Paris, Brandus, [1883]). Source: Gallica.

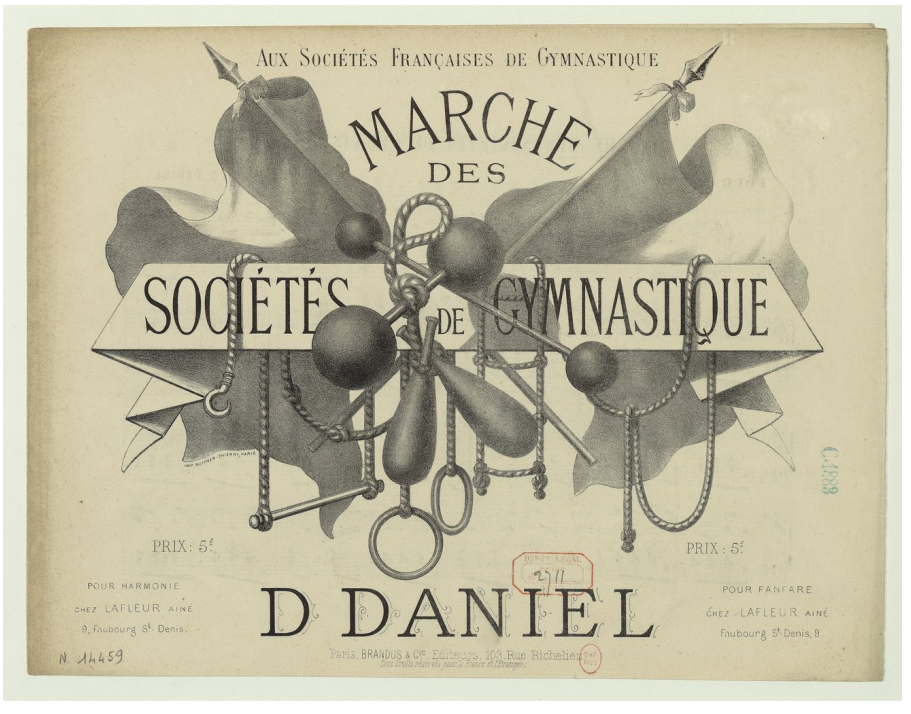

Ces marches d'athlètes et de gymnastes du tournant $d u x^{e}$ siècle n'ont pas de paroles véhiculant ouvertement un message patriotique et guerrier. Elles participent d'un programme républicain de discipline de la force, d'éducation à l'ordre et de renforcement de l'esprit de corps avant même d'être un appel direct à la défense militaire de la nation (Chambat 1997). Toutefois, il est possible de retrouver ailleurs, et notamment dans les chants gymnastiques scolaires (utilisés à la fois pour rythmer l'exercice, en énoncer les mouvements et motiver à l'effort), la mise en musique 
explicite de l'utilité militaire (entre autres) ${ }^{13}$ de l'éducation physique (en l'occurrence des écoliers) :

Le chant est une évocation sonore de ce qui se joue dans la fortification des corps et des âmes. Il est un plaidoyer constant qui condamne l'élève à fixer l'objectif imposé par la République. Il est le garant moral qui explicite la future utilisation des forces que promeut l'exercice (Terret 1997, p. 69).

Dans le Recueil de chants d'écoles (Docx, Patigny et Miry 1881) étudié par Thierry Terret (1997), on retrouve par exemple, dans la section «Chants gymnastiques », une "Marche guerrière » et un chant intitulé «Les petits soldats ». Hors de l'école, on peut citer l'exemple du " chant patriotique " La gymnastique (paroles de P.-H. Corgeron, musique de Renaud Goublier, [1887]).

L'idée que l'athlète se prépare aux guerres futures trouve d'ailleurs un exemple musical classique dans la troupe d'athlètes et de combattants au premier acte de Castor et Pollux (1737) de Jean-Philippe Rameau (opéra qui fut repris pour la première fois depuis 1778 à Montpellier en 1908, et l'année suivante à la Schola cantorum ${ }^{14}$, avant d'être mis en scène à l'Opéra de Paris en pleine guerre, le 21 mars $1918^{15}$ ) :

\author{
Éclatez, fières trompettes! [...] \\ Ranimez notre courage! \\ Que nos danses et nos pas \\ Des combats \\ Soient encore l'image! \\ Volez tous, \\ Courez aux armes! \\ Unissez-vous!
}

\begin{abstract}
13 Bien que, au milieu du XIX ${ }^{\mathrm{e}}$ siècle, Francisco Amorós y Ondeano « donne à l'éducation physique française une forme paramilitaire et l'engage dans une voie patriotique et publique, dont elle aura du mal à se dégager par la suite » (Turcot 2016, p. 452), Arnaud a souligné que la gymnastique scolaire n'avait pas en principe des finalités militaires, mais hygiéniques (voir Arnaud 1997b).

14 Pour les exécutions partielles de Castor et Pollux à la Schola cantorum à partir de 1894, voir Gibbons 2013, p. 152, tableau 8.3. Sur la représentation à Montpellier, dirigé par Charles Bordes, voir le long article publié par Édouard Perrin dans Le Mercure musical/Revue musicale SIM (Perrin 1908). En 1903, la partition de l'opéra, éditée par Auguste Chapuis, est parue dans les Euvres complètes de Rameau publiées chez Durand à partir de 1895.

15 Deux jours après, le 23 mars, Paris commence à être bombardé à distance de $100 \mathrm{~km}$ par les Allemands, comme le rappelle d'ailleurs Julien Tiersot dans sa rétrospective publiée dans Le Ménestrel : "Le surlendemain de cette reprise [de Castor et Pollux], le bombardement de Paris par le super-canon commençait. Ce fut une nouvelle cause d'interruption dans la destinée du vieux chef-d'œuvre, qui dut attendre le lendemain de la victoire pour reprendre sa place définitive sur la scène dont il avait été jadis une des principales gloires » (Tiersot 1920, p. 25). Nous n'avons pas trouvé de traces, dans les comptes rendus parus dans la presse parisienne au lendemain de la représentation à l'Opéra de 1918, du fait que cette scène ait eu des résonnances particulières sur l'auditoire en pleine guerre, constitué pour la plupart de soldats. On souligne plutôt le caractère « absolument français, en dehors de tout exotisme » du spectacle (Aderer 1918) et l'effectif instrumental inhabituel pour les poilus de Paris, ces «braves gens » dont « l'absence, à l'orchestre, de clarinettes, cors et trombones a surpris leurs oreilles habituées aux sonorités vigoureuses de la musique moderne ", mais dont le tympan a été « vivement impressionné " par « les contre-ut de la petite trompette en ré du premier acte » (Interim 1918).
\end{abstract}


Qu'à jamais les jours d'alarmes

soient les plus beaux jours pour nous ${ }^{16}$ !

Plusieurs sujets s'ouvrent ici qui méritent des études à part entière : premièrement, l'histoire de l'association entre musique de guerre et éducation physique (scolaire ou militaire ${ }^{17}$; deuxièmement, celle des représentations musicales de l'athlète-héros grec et de leur persistance dans la culture gymnique française à partir du XIX ${ }^{e}$ siècle. Contentons-nous de signaler, à propos de ce dernier thème, qu'il est possible de retrouver des exemples musicaux de l'association athlète-héros au milieu du XIX ${ }^{e}$ siècle dans les cérémonies de distribution des prix, et notamment dans la cantate pour les finissants Distribution des prix (Francesco Andrevi, 1846). Après une ouverture Marziale et le chœur "Le laurier va ceindre les têtes | De nos jeunes triomphateurs ", un duo entonne le texte suivant :

L'athlète des vieux temps parcourait la carrière

L'œil en feu, le cœur palpitant

Qu'importe à son ardeur guerrière

Que de sueur et de poussière

Se couvre son front ruisselant.

Il voyait l'avenir se couronner de gloire

Il entendait son nom des foules répété

Inscrit au temple de mémoire

Et les hymnes de la victoire

Chanter son immortalité.

Chour: Amis, vous êtes ces athlètes [etc.]

16 Acte I, scène 4. Après l'air de Télaïre "Tristes apprêts, pâles flambeaux ", Pollux avance vers le monument funèbre de Castor précédé par une troupe d'athlètes et de combattants au rythme d'une «symphonie guerrière ». Après un échange entre Pollux et le peuple, les athlètes entament un « combat figuré » ("Premier air pour les athlètes ») suivi par un duo qui glorifie la guerre en rappelant les combats passés et en incitant aux combats futurs. Le texte reproduit ici est celui de la version de 1737, selon l'édition Rameau 2002 (p. 25). L'édition Rameau 2013 (p. 6) présente plusieurs variantes (en italique ci-après) :

Resonnez, fières trompettes ; [...]

Ranimez notre courage,

Que nos danses et nos pas

Des combats

Soient encore l'image :

Venez tous,

Volez aux armes,

Volez tous,

Unissez-vous.

Combattons : les jours d'alarmes

Sont les plus beaux jours pour nous.

Dans la version de 1754 de l'opéra, ce numéro devient une " Ariette » pour un seul athlète et toute référence au guerres futures disparait (voir Rameau 2002, p. 77).

17 Tout en tenant compte des différences entre caractéristiques militaires et usage militaire de la musique. 


\section{LA RIDICULISATION DU SPORTIF}

Du côté de la chanson d'avant 1914, par contre, 1'association du sport au militarisme et à l'héroïsme semble être absente. Au café-concert, l'engouement sportif fait partie des sujets d'actualité sur lesquels on ironise. Les textes-caricatures des chansons ridiculisent les hommes forts ${ }^{18}$ - et, ce qui a un effet encore plus comique, les femmes fortes, comme le montrent les cas très précoces (datés respectivement de 1881 et 1887) de La femme athlète avec "Miss Marilla " (figure 3) et de la chansonnette comique du même titre (paroles de Delormel et Laroche, musique de Louis Byrec [pseudonyme de Louis-Antoine Dubost]), où la protagoniste " cass' des noisettes | En [s']asseyant d'ssus » (figure 4$)^{19}$.

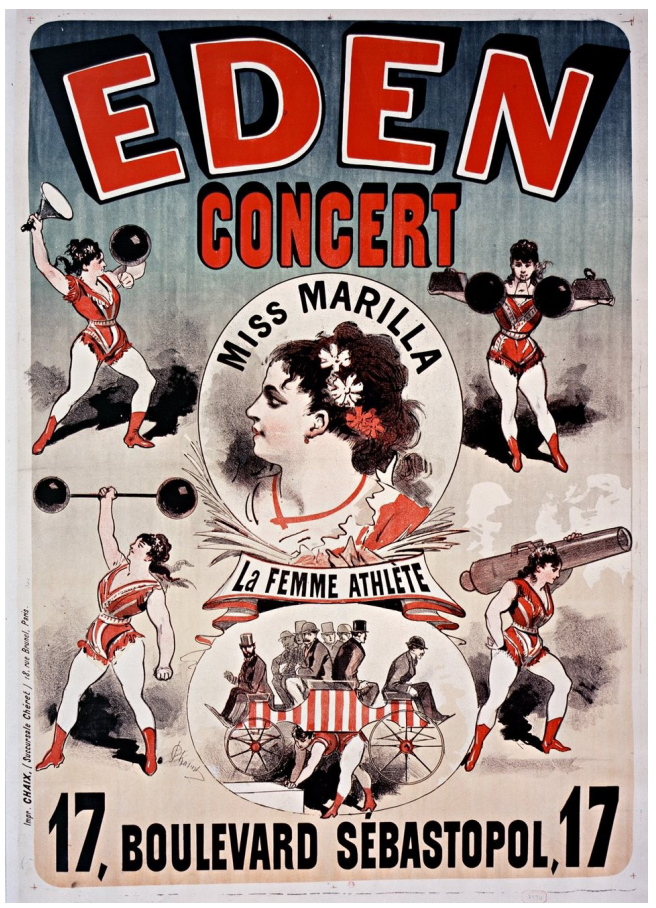

Figure 3 : Jules Chéret (1836-1932), affiche de La femme athlète (1881). Source : Gallica.

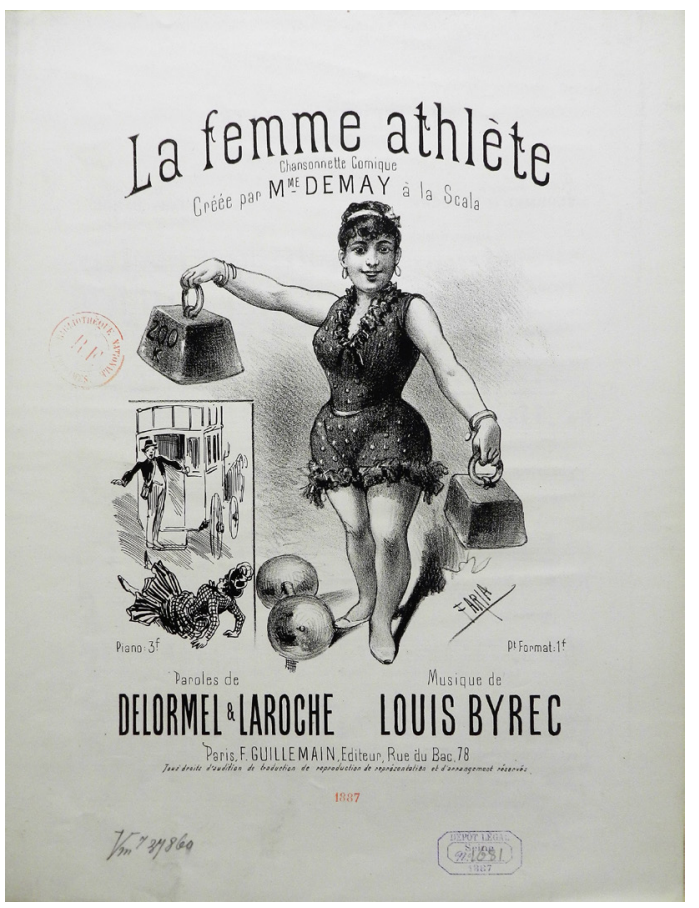

Figure 4: Cândido de Faria (1849-1911), couverture de La femme athlète (Paris, F. Guillemain, [1887]). Source : BnF.

18 Le caractère caricatural des chansons de café-concert permet de comprendre pourquoi la force, attribut normalement valorisé par les classes populaires et par la bourgeoisie de la fin du XIX ${ }^{\mathrm{e}}$ siècle (voir Andrieu 1988), y est ridiculisée par des artistes pour la plupart issus de ces mêmes classes. Victorin Joncières écrivait dans Le Figaro illustré, en 1896, que la musique de café-concert " est à la vraie musique ce que la caricature est à la peinture " (cité dans Caradec et Weill 2007, p. 127). Sur la provenance des chanteurs, une citation tirée de Types du boulevard (1896) de Ferdinand Bloch et proposée par Caradec et Weill (2007, p. 129) offre un portrait efficace du garçon d'atelier qui devient chanteur parce que ses « camarades lui ont dit et répété sur tous les tons qu'il avait un physique "rigolo" et une voix agréable ».

19 Sur l'histoire culturelle de l'activité physique féminine en France sous la Troisième République, voir entre autres Holt 1991, Stewart 2001 (particulièrement la troisième partie), Terret 2007 et les articles de Gilbert Andrieu, Pierre Arnaud, Jean-Michel Delaplace, Jacques Gleyse, Jean-Paul Laplagne, Philippe Liotard, Luc Robène et Hélène Salomon dans Arnaud et Terret 1996. Pour une synthèse de la question, Clastres et Dietschy 2006, p. 46-47. 
Dans cette lignée, on retrouve une série de chansons comiques ayant comme protagoniste le personnage de Hector - nom qui peut rimer avec sport, corps et fort (ainsi qu'avec mort, mais cette rime ne semble pas être exploitée) ${ }^{20}$. On le retrouve à partir de Hector fait du sport en 1906 (paroles d'André Mesnil, musique de Henri Christiné) jusqu'à L'athlète complète de 1914 (paroles de Briollet et A. Foucher, musique de Renner). Cette dernière chanson fait sans doute écho à L'athlète complet de la même année (paroles de Ch. Danel, musique de Marius Isoard) et offre un exemple d'une association récurrente dans les chansons à sujet sportif, celle entre sport et érotisme :

Couplet 3

À la campagne un beau dimanche

Avec mon voisin Hector

Nous nous amusions sous les branches

À des exercices de corps.

Soudain j' prends sa canne et j' la fixe

Sur un chêne solidement

Puis j' dis ça m'servira d' barr' fixe

Pour faire un soleil épatant.

Refrain

C'est moi l'Athlèt'... c'est moi l'Athlèt' complète

J'y ai montré c'que c'était qu'un soleil réussi

Mais comme il levait l'nez pour voir mes pirouettes

Il a vu mon Soleil... et puis ma Lune aussi.

Il existe plusieurs chansons entièrement construites sur l'association sport-érotisme, qui s'explique évidemment par le fait que l'activité physique ( faire du sport ») devient volontiers chez les chansonniers une métaphore érotique. Le thème de l'indécence (voire de l'excitation) représentée par la visibilité du corps chez la femme sportive, comme dans L'athlète complète, se retrouve par exemple dans Le sport de Suzette, chansonnette comique de G. Routier mise en musique par J. Dorin (1904), où Suzette en bicyclette est une source d'excitation pour tout ce qui l'entoure ${ }^{21}$. Les femmes sportives (ou "sportswomen ») sont d'ailleurs un thème récurrent des illustrations ironico-érotiques (voir figures $5 \mathrm{a}$ et $5 \mathrm{~b}$ ) et des ballets de music-hall, où toute excuse

20 Hector est, encore aujourd'hui, le nom du personnage choisi pour inciter les enfants à pratiquer les sports dans une campagne de sensibilisation à un style de vie sain menée par France Télévisions (https://play.google.com/store/apps/details?id=com.myhector.app\&hl=fr CA, consulté le 23 octobre 2017). My Hector est aussi le nom d'une application-coach sportif pour téléphone intelligent (www.myhector.com, consulté le 23 octobre 2017).

21 Le titre de cette chanson est probablement un clin d'œil à l'opérette Le voyage de Suzette (livret de Alfred Duru et Henri Chivot, musique de Léon Vasseur ; première représentation au Théâtre de la Gaîté, 1890). D'autres exemples de satire de la femme sportive sont La reine du sport (paroles de Perigaud et [Lucien] Delormel, musique d'Émile Duhem, [1881]) et La femme de sport (paroles et musique de Lucien Delormel, 1893). Pour un portrait de « la bicycliste ", voir le chapitre éponyme dans La Parisienne peinte par elle-même de Georges Montorgueil (1897). On pourra comparer ces portraits de femmes sportives du début du siècle avec celles qui peuplent la littérature française de l'entre-deux-guerres que relate Thomas Bauer (2001). 
est bonne pour montrer des corps féminins peu habillés - soient-ils en maillot de bain ou en habits « modernes» permettant l'activité physique ${ }^{22}$.
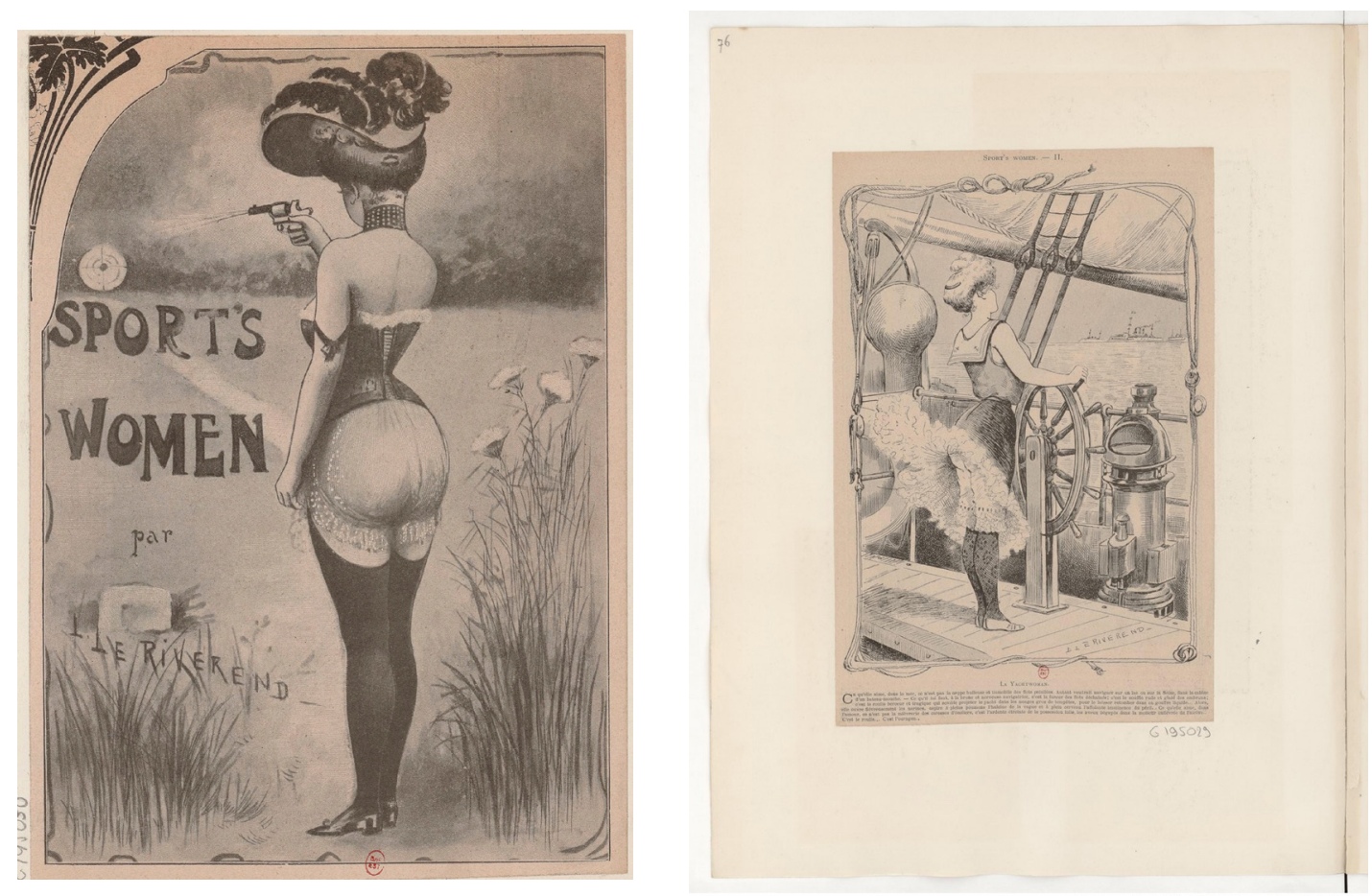

Figures $5 a$ et $5 b$ : Le Riverend, Sport's Women, s. d. : a) [sans titre] ; b) "La Yachtwoman ».

Défets recueillis dans Collection Jaquet. Dessinateurs et humoristes français des $\mathrm{XIX}^{\mathrm{e}}$ et $\mathrm{XX}^{\mathrm{e}}$ siècles, série 1 : L-M, tome 4, image no 84 (BnF, MFILM G-195029-195030, disponibles sur Gallica, a) et b)).

"La Yachtwoman » dessinée par Le Riverend, comme on peut le lire dans la didascalie de la figure $5 \mathrm{~b}$, transpose au lit ce qu'elle aime dans « la fureur des flots déchaînés ": "Ce qu'elle aime, dans l'amour, ce n'est pas la mièvrerie des caresses d'écoliers, c'est l'ardente étreinte de la possession folle, les aveux bégayés dans la moiteur enfiévrée de l'alcôve... C'est le roulis... C'est l'ouragan ». La boxeuse dessinée par François Lafon dans une carte postale reproduite par Juliette Rennes dans son ouvrage sur les « femmes en métier d'hommes " (2013) introduit l'érotisme directement sur le ring - le corps à corps de la boxe assumant une connotation sexuelle lorsqu'il s'agit d'une étreinte entre une femme en costume moulant et un homme à torse $\mathrm{nu}^{23}$.

Dans les chansons que nous avons consultées, la guerre rentre parfois dans la métaphore érotique selon les anciennes images du combat d'amour et de la «bataille sous les couvertures", comme dans le cas de la chanson Patrie-Sport (paroles de

22 Parmi les spectacles aux Folies Bergère, à l'Olympia et au Casino de Paris listés par Sarah Gutsche-Miller (2015), on peut en compter huit à thème sportif : Le grand prix de Paris (1882), Sur la plage (1883), Paris-turf (1889), Marine (1890, sur le thème de l'athlétisme militaire), Brighton (Les plaisirs de la plage) (1893), Les demoiselles du XX $x^{e}$ siècle (1894), Sports (1897, repris en 1908), L'aéroplane (1910).

23 La carte postale intitulée Les sports féminins. La boxe : le corps à corps (s. d. [vers 1900]) est reproduite dans Rennes 2013, p. 28, illustration 35. 
Paul Briollet et Léo Lelièvre, musique de Félix Chaudoir, 1902), où le « Mourir pour la patrie, c'est le sport le plus beau » du premier refrain n'est rien d'autre qu'un éloge de l'orgasme avec une citation de La Marseillaise en cadence (exemple musical 1).

Exemple musical 1 : Premier refrain de Patrie-Sport (paroles de Paul Briollet et Léo Lelièvre, musique de Félix Chaudoir, Paris, Aux Répertoires réunis, 1902). Interprétation non commerciale pour le présent article par Federico Lazzaro (chant) et Paulo Bottas (piano). Écouter.

Dans le même esprit, le Sport patriotique selon Benoit et Pierre Cornéglia (paroles) et Pierre Codini (musique) consiste non pas à combattre, mais à repeupler la France en cas de guerre (la chanson est de 1913, en « tempo di marcia ») :

\section{Couplet 4}

Si nous avions jamais la guerre,

Chacun devrait fair' son devoir,

Puisque nous manquons d' militaires

On d'vrait r'populer chacque soir.

J' m'entrains avec les brun's les blondes,

Les poils de briqu' et les châtains,

Avec les tocs et les girondes,

C'est pour la défens' du pat'lin!

Même dans les cas, comme celui-ci, où on évoque la guerre, il est évident que le sport est surtout un élément de la vie moderne, et en tant que tel il fait l'objet de la satire sociale des chansonniers ${ }^{24}$. Le protagoniste de Sport and sport (noter l'anglicisme) de Dlaverdet (paroles) et Louis Bonin (musique), en 1910, juge la pratique du sport trop dangereuse et préfère plutôt " se servir de sa femme quand il veut faire du sport ». Le Sport renversant de Boud'nor et Georges Picquet (1904), contient des plaisanteries du même ordre. Et le thème du sport omniprésent dans la vie moderne est ridiculisé dans Paris-Sport (paroles de Muffat et Desmarets, musique de Lucien Delormel, 1894), Je fais du sport (paroles de Georges Sibre, musique de L. Fontaine, 1903) ou Un peu de sport (paroles d'Eugène Christien, musique de Henri Christiné, 1909). L'association entre le sport et la "modern life » d'outre-mer est explicitée dans Nigger-Sport, un " cake-walk polka marche américaine » pour piano de Charles Grelinger (Paris, Du Wast, [1903]), où le noir en couverture ouvre tout un pan de questions, cruciales à l'époque, liées au contact, en France, avec des champions sportifs - et plus tard des musiciens - noirs (figure 6) ${ }^{25}$.

24 Les exemples « savants » d'avant-guerre, le ballet Jeux (1913) de Claude Debussy et le recueil illustré pour piano Sports et divertissements (1914) d'Erik Satie, ne font que confirmer l'association ironique du sport avec le divertissement, l'érotisme et la vie moderne. Pour une analyse des caractéristiques « à la mode » du recueil écrit par Satie en collaboration avec l'illustrateur Charles Martin, voir Davis 1999.

25 Tel que démontré par Timothée Jobert (2006) à propos du milieu de la boxe dans les années précédant la Première Guerre mondiale, cette présence ne menait pas forcément à une attitude raciste. Quant au lien entre musique américaine et sport, Jules Janin, en 1929, affirme clairement que celui-ci est à l'origine de celle-là, par le biais de la danse : «Les Américains firent du sport par nécessité et par goût [...]. Comme ils

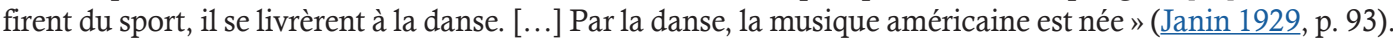




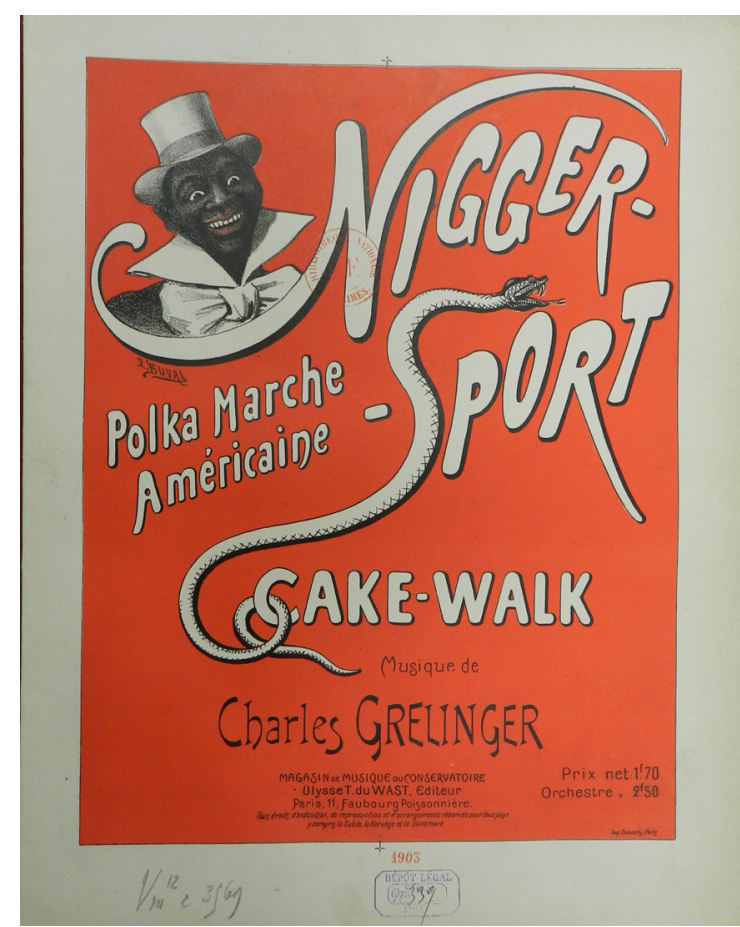

Figure 6: Anonyme, couverture de Nigger-Sport (Paris, Du Wast, [1903]). Source : BnF.

Le fait que plusieurs chansons soient en rythme de marche ne doit pas être interprété comme une utilisation de topoï musicaux militaires, mais est un trait typique de la chanson de café-concert, peu importe son sujet. Comme l'explique Victorin Joncières dans Le Figaro illustré en 1896, "les paroles [...] [sont] débitées sur une musique au rythme de marche, ce qui permet aux chanteurs de se promener en cadence pendant le refrain » (cité par Caradec-Weill 2007, p. 126). La partition de la "chanson de vitesse " Au pas gymnastique (paroles d'Auguste Barrois, musique de Jules Souplet, [1889]), par exemple, spécifie que "l'artiste court au pas gymnastique pendant le refrain ». Joncières spécifie en outre que le compositeur Félix Chaudoir - l'auteur de Patrie-Sport (voir plus haut et exemple musical 1), ainsi que de la "chanson marche » Les sociétés de gymnastique (paroles de Lucien Delormel et Léon Garnier, 1887) "préfère le mouvement de marche militaire " (ibid.). Une marche peut même devenir " vélocipédique ", comme dans le cas de En tandem! Marche vélocipédique (paroles de Eugène Rimbault, musique de Eugène Poncin et Del, 1894).

\section{SPORT, GUERRE ET MUSIQUE « MILITAIRE »}

Pierre de Coubertin, l'inventeur des Jeux olympiques modernes (première édition à Athènes, en 1896), a publié en 1912 un essai sur "Le sport et la guerre " (Coubertin [1912]1992). À cette époque, le sport est désormais entré dans le quotidien des citoyens et les premières éditions des Jeux olympiques ont commencé à attribuer aux compétitions entre les nations une signification non militaire. Coubertin ne parle donc pas dans son essai de la gymnastique comme d'une préparation physique directe à la guerre. Il suggère plutôt que la pratique du sport (et surtout du sport d'équipe) est une préparation indirecte à la guerre : le sport habitue les hommes au fairplay (contribue à répandre «le sentiment du jeu », p. 196) et «fait fleurir toutes les qualités 
qui servent à la guerre : insouciance, belle humeur, accoutumance à l'imprévu, notion exacte de l'effort à faire sans dépenser des forces inutiles...» (p. 196). En conséquence, selon Coubertin, la guerre de l'avenir sera plus précise et plus rapide, et « une armée de sportsmen sera plus humaine, plus pitoyable dans la lutte, plus calme et plus douce après » (p. 197). Les prévisions de Coubertin seront bientôt démenties. Mais la Grande Guerre présentera aussi des exemples frappants de l'association sport-guerre, notamment dans l'armée anglaise, avec la pratique du recrutement parmi les clubs de football et quelques cas où les soldats ont commencé la bataille en tirant un ballon (Watkins 2003, p. 63-64 et 137-138), parce que les Anglais, au début, considéraient la guerre comme une sorte de match - " a brief armed version of the Olympic Games " (Osbert Sitwell, cité dans ibid., p. 137 ; voir aussi Russell 2015).

En France, la production musicale à sujet sportif semble avoir subi un frein significatif, sinon s'être complètement arrêtée, pendant la Guerre. Nos recherches n'ont en effet donné aucun résultat de partition "sportive " ou " athlétique " entre 1914 (année de L'athlète complet et L'athlète complète, ainsi que de Sports et divertissements) et 1922, année du concours " L'art et les sports » de Comodia. Revenons donc à ce concours.

La pièce qui a gagné le concours de Comoedia, le Cortège d'athlètes du compositeur ultranationaliste Louis Vuillemin, auteur de nombreuses attaques xénophobes dans la presse (notamment dans sa rubrique Notes sans mesure, dans Le Courrier musical), rend le lien entre compétitions sportives et combat pour la nation très explicite. Les cinq mouvements qui composent la pièce (et qui étaient requis par le règlement du concours) - " Préambule. Entrée des cortèges sur le stade "; "Le défilé "; " Le salut des athlètes »; "Divertissement (pendant les jeux et les productions athlétiques) »; "Finale héroïque »- abondent en topoï militaires tels que les appels de trompette et le rythme de marche.

L' "Entrée des cortèges sur le stade " est construite en forme de rondo, avec un refrain constitué par un appel en dialogue entre les trompettes et les autres cuivres (figure 7). "Le défilé » est logiquement une marche. La première section (mes. 1-16) exploite encore une fois l'appel de trompette ; cette fois-ci la texture n'est plus un dialogue, mais une superposition entre la partie très répétitive des trompettes et une succession assez recherchée d'accords jouée par le reste de l'orchestre (figure 8). Il n'est probablement pas abusif de remarquer que l'Hymne à la paix écrit par Camille Saint-Saëns sur des paroles de Jean-Louis Faure, joué en 1920 au Palais du Trocadéro à la présence de Raymond Poincaré (président de la République française pendant la Première Guerre mondiale, jusqu'au 18 février 1919) ${ }^{26}$, commence avec la même figure d'appel (figure 9) : les sonorités militaires ont traditionnellement servi à célébrer les victoires, et continuent de le faire dans un contexte qui prône pourtant l'abandon définitif des armes. La « militarisation » des stades - qui se fait sur le plan de la représentation (discursive, visuelle, musicale) - rappelle la guerre tout en la reniant. Le "Finale héroïque » du Cortège d'athlètes est d'ailleurs un " hommage

26 Sur le contexte de création de l'Hymne à la Paix de Saint-Saëns et sur l'implication du compositeur dans la célébration des morts et de la victoire, voir Leteuré 2014, p. 162-168. 
des athlètes à Ceux [sic] de la Somme, de l'Yser, de la Marne, de la Champagne, de l'Aisne et de Verdun ».

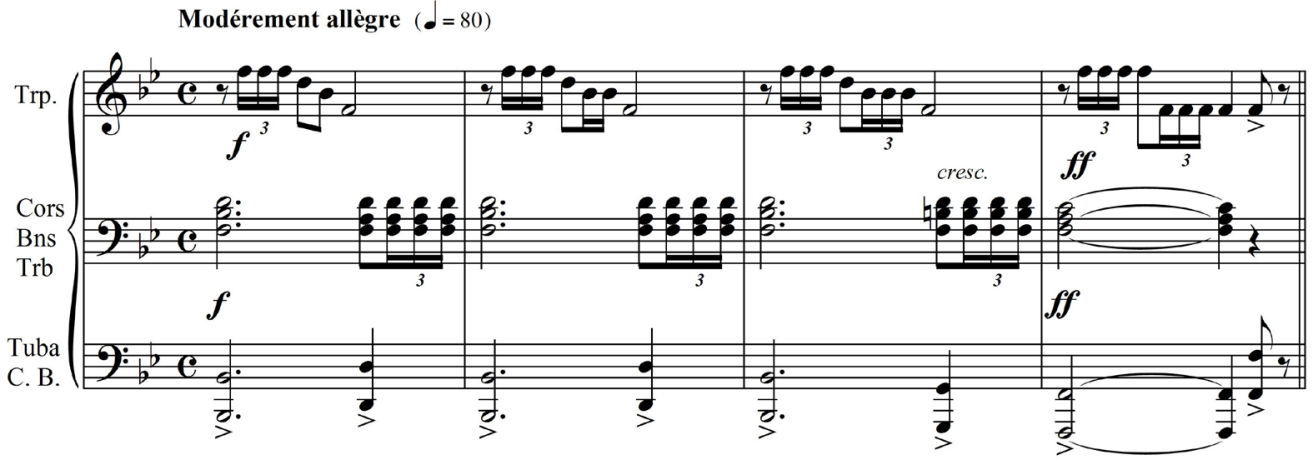

Figure 7 : Louis Vuillemin, Cortège d'athlètes, "Préambule. Entrée des cortèges sur le stade", mes. 1-4 de la réduction pour chant et piano (Nantes, Jacques Vuillemin, 1922).
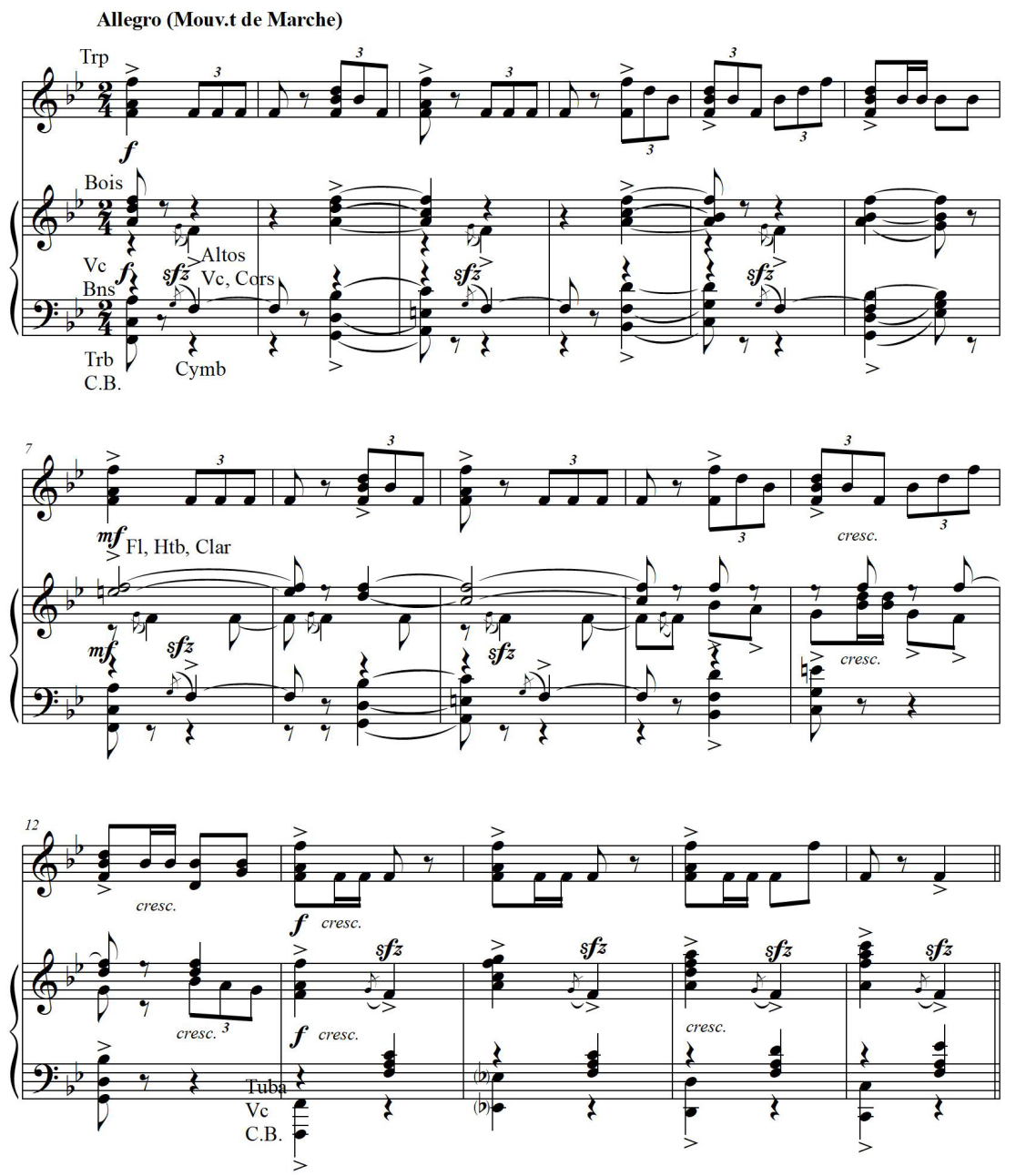

Figure 8: Louis Vuillemin, Cortège d'athlètes, "Le Défilé ", mes. 1-16 de la réduction pour chant et piano (Nantes, Jacques Vuillemin, 1922). 


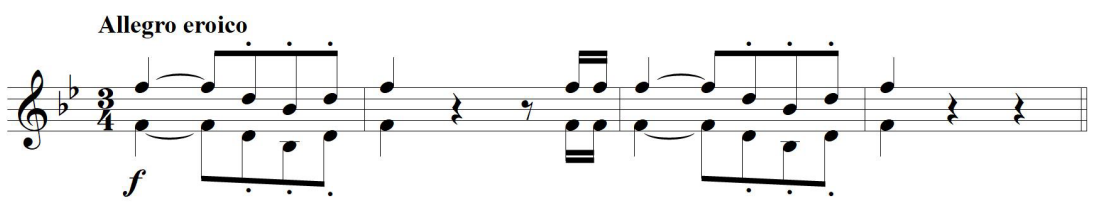

Figure 9 : Camille Saint-Saëns, Hymne à la paix, op. 159, mes. 1-4 de la partition pour chant et piano (Paris, Durand, 1920).

«Le salut des athlètes ", le seul mouvement chanté du Cortège d'athlètes, s'adapte parfaitement à cette rhétorique martiale et rend explicite, dans son second couplet (" pour le départ ") l'association entre le sport et la guerre, le soldat et l'athlète son titre pourrait être facilement modifié en « Le salut des soldats » :

Soyons fort pour être libre, l'esprit clair, le cœur hardi. Ô merveilleuse espérance!

Notre élan joyeux et fort est vainqueur de la souffrance et peut défiler la mort !

Exemple musical 2 : Louis Vuillemin, Cortège d'athlètes (1922) : "Le salut des athlètes", second couplet. Interprétation non commerciale pour le présent article par Federico Lazzaro (chant) et Paulo Bottas (piano). Écouter.

La glorification du sport «militarisé » s'accompagne, dans la pièce de Vuillemin, de la célébration du caractère insouciant de l'activité physique, de cette fraîcheur de la jeunesse saine et forte typique de la littérature et de la poésie à sujet sportif de cette même époque. Pour se limiter à un seul exemple, nous citerons Au soleil dustade-recueil poétique d'Alfred Robert préfacé par Chéron et contenant un "Cortège d'athlètes " dédié à Vuillemin (Robert 1924, p. 23-25) -, où les thèmes de la clarté, de la vitalité, de l'effort rendu beau par le soleil (et par le regard des femmes sur le corps des athlètes) et de la fierté nationale pour la jeunesse sportive occupent une soixantaine de poèmes aux titres exaltés : "Fleur éclatante de la force », " Le sculpteur de joie », "Dans la danse de la lumière ", "Ardeur ", « Bondissement », « Exaltation », ou encore " Rayonnement ", « Éblouissement », « La vivante offrande », " Splendeur du corps humain ", pour ne citer que quelques exemples.

Ainsi, dans la musique de Vuillemin, l'emphase martiale et une certaine légèreté lyrique célébrant le plein air ${ }^{27}$ cohabitent - on se souviendra que l'appel de concours demandait un style "élevé et populaire ". Comme il est possible de l'entendre dans l'exemple musical 2, l'emphase martiale des paroles du « Salut des athlètes » est mitigée par une ambiance harmonique loin d'être agressive. Dans la figure 10, qui reproduit la première période de l'exemple musical 2, on peut voir par quels moyens Vuillemin parvient à cet effet, et notamment les appogiatures de neuvième au chant, les retards

27 Cette même veine lyrique est présente dans certains épisodes de Rugby de Honegger et de Half-Time de Martinů, comme nous l'avons souligné dans Lazzaro 2017, p. 38. 
et l'emploi de l'accord de $\mathrm{III}^{\text {e }}$ degré dans le mode majeur. La figure 11 présente, pour sa part, un des éléments au caractère le plus " populaire » du Cortège d'athlètes, le thème du quatrième mouvement («Divertissement»), constitué par une progression sur une idée mélodique très simple chantée par les violons et les hautbois.

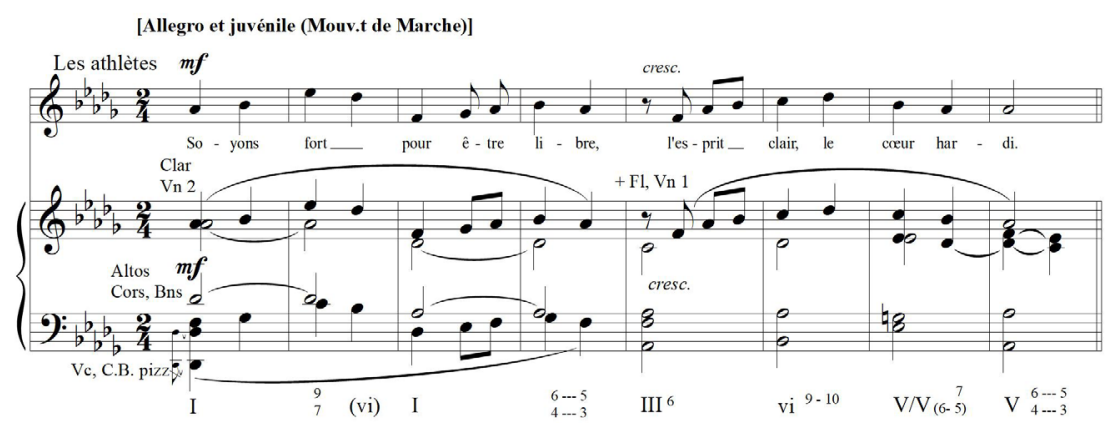

Figure 10 : Louis Vuillemin, Cortège d'athlètes, "Le salut des athlètes ", mes. 16-23 de la réduction pour chant et piano (Nantes, Jacques Vuillemin, 1922).

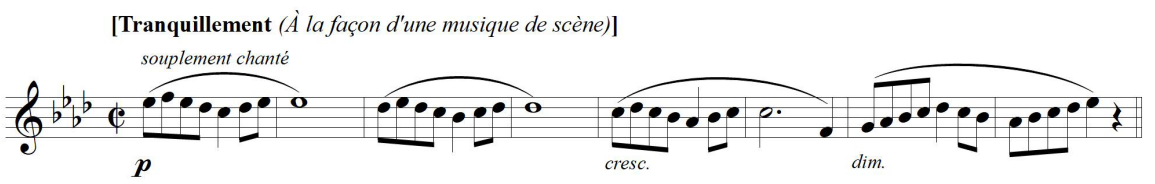

Figure 11 : Louis Vuillemin, Cortège d'athlètes, "Divertissement (pendant les jeux et les productions athlétiques) ", mes. 4-11, mélodie des violons et des hautbois tirée de la réduction pour chant et piano (Nantes, Jacques Vuillemin, 1922).

Lors de l'inauguration du stade de Saint-Maur le 28 mai 1922, le Cortège d'athlètes de Vuillemin accompagna probablement le " cortège antique » dont les journaux rendent compte de manière enthousiaste - plus de 200 exécutants selon L'Écho de Paris (Anonyme 1922b), plus de 300 selon Le Petit Journal (Aviron 1922) ou L'Auto (Anonyme 1922a) -, dans une énième fusion du héros antique avec l'athlète moderne ${ }^{28}$.

À la même époque du concours de Comoedia, une chanson mise en musique par Pierre Codini - le même pour qui, avant le conflit, le "sport patriotique " consistait à repeupler la France - entonne une emphatique Gloire au sport. On y retrouve l'idée de l'athlète comme source de régénération de la " race " ("Pour l'avenir de notre race, | L'athlète a pris enfin sa place ») et comme nouveau héros national ("Du stade, [les champions] entreront, par nos voix, dans l'Histoire »), l'appel à l'entraînement physique comme source de grandeur du pays (« Debout, Français, allons debout !

28 On pourrait supposer que le Jean Nouguès nommé par les journaux en lien avec ce spectacle soit le compositeur Jean Nouguès (1875-1932), auteur d'œuvres dramatiques à sujet antique telles l'opéra Quo vadis ? (1908) et l'opéra-ballet La danseuse de Pompeï (1912). Dans ce cas, il est probable que sa propre musique ait été employée pour ce spectacle. Toutefois, nous n'avons pas trouvé de partition en attestant. L'expression « le cortège antique réglé par M. Nouguès » utilisée par L'Écho de Paris (Anonyme 1922b, nous soulignons) pourrait suggérer que Nouguès aurait plutôt été le chef d'orchestre ou encore le chorégraphe (chose qui nous semble improbable). Les chroniqueurs de L'Auto (Anonyme 1922a) et du Petit Journal (Aviron 1922) parlent par contre de « cortèges antiques de M. Nouguès » (nous soulignons). 
| Pour être grands, redressons-nous »; "La France de demain, | C'est la France musclée ! ; " Enfin la France vibre | Sachant qu'un peuple libre | Doit être un peuple fort ") et la qualification explicite du sport comme substitut pacifique de la guerre («Eh bien, entre pays, luttons, | Non plus en des combats tragiques | Mais sans haine, aux Jeux olympiques. | Combattons par le sport, sans rougir notre main ») ${ }^{29}$.

Des œuvres comme Cortège d'athlètes et Gloire au sport promeuvent explicitement la fusion de la figure de l'athlète/sportif et du guerrier qui est orgueil et défense de la nation. Pour reprendre les mots de l'historien spécialiste en musiques militaires Didier Francfort, " il n'y a pas de musique militaire par essence mais des musiques d'usage militaire ou des musiques militarisées "(Francfort 2014, p. 25-26), et " on serait bien en peine de séparer les "vraies marches militaires" et les marches dignes d'une "armée d'opérette" " (ibid., p. 26) ${ }^{30}$. Autrement dit, des topoï tels que le rythme de marche ou les appels de trompette sont une partie certes importante de la perception d'une musique comme "militaire ", mais ce sont surtout le paratexte, le texte chanté et le contexte de production qui scellent le caractère ouvertement militaire d'une pièce :

Les mêmes mélodies peuvent servir tour à tour dans les salons et à l'occasion des défilés militaires. [...] La Première Guerre mondiale marque peut-être moins une césure qu'un jalon dans une évolution à long terme, rattachant les « musiques militaires » à un ensemble musical large, populaire, servant de façons parfois très contradictoires dans des manifestations publiques, essentiellement en plein air (ibid., p. 25).

Ainsi, le Cortège d'athlètes de Vuillemin se propose explicitement comme une musique " militarisée », mais pour une armée " pacifiste » telle qu'une équipe d'athlètes, et ce, dans un contexte international où les rapports entre le sport et la politique deviennent de plus en plus étroits. Dans Castor et Pollux, les athlètes espéraient pouvoir utiliser leur force dans des guerres futures - principe de la gymnastique comme préparation directe à la guerre ; à partir des années 1920, le combat se fait directement dans les stades - les sports sont déjà la guerre ${ }^{31}$. L'ambiguïté de la figure de l'athlète est évidente. Même sans considérer les actions politiques entourant les compétitions internationales - comme le fait de célébrer la victoire de la Grande Guerre par des Jeux excluant les nations perdantes (les Jeux interalliés de 1919 étudiés par Terret 2003) -, c'est dans les discours et dans la musique qui les accompagne que le sport international se présente tout court comme une guerre. Au courant des années 1920, les hymnes

29 Le texte intégral de la chanson est consultable ici : www.labeilledelaternoise.fr/2012/07/26/ les-jeux-olympiques-de-1924-830 ; et un enregistrement chanté par Adolphe Bérard se trouve ici : www.phonobase.org/7488.html (consultés le 23 octobre 2017).

30 Un exemple de ces marches sportives « dignes d'une armée d'opérette " a été transmis dans l'émission Musique, sport et divertissements (Tétart 2016). Il s'agit de Godfroy Andolfi, Marche de la société hippique française (1934), qu'il est possible d'écouter à la minute 23:49 de l'émission, en suivant ce lien : www.francemusique.fr/emissions/un-air-d-histoire/musique-sport-et-divertissements-par-philippe-tetart-29662 (consulté le 23 octobre 2017).

31 La thèse du stade comme «nouveau champ de bataille » est défendue notamment, en ce qui concerne l'histoire de la France, par Arnaud et Riordan 1998, p. 278 et suiv. 
nationaux commencent à être joués lors des victoires sportives ${ }^{32}$ et la pratique devient protocolaire, jusqu'à susciter des débats sur les implications de faire jouer les hymnes nationaux des nations ennemies ou anciennes ennemies par les musiciens militaires français (Arnaud et Riordan 1998, p. 308-309) : c'est une étape musicale de plus dans le processus d'identification entre le soldat et l'athlète.

Ajoutons que les plus récentes études sur la musique pendant la Grande Guerre ont démontré que la " musique militaire » était en général absente des champs de bataille (Francfort 2014, p. 26). Dans la guerre moderne, la fonction principale de la musique militaire est désormais de faire marcher les troupes lors des défilées, tandis qu'avant elle servait à régler leurs mouvements, donner des ordres, terroriser l'ennemi (qu'on pense au mehter ottoman). Au stade - le champ de bataille de cette guerre pacifique qui est le sport international -, la musique reprend la place qu'elle avait perdue dans la vraie guerre. Il n'est pas anodin que dans la longue enquête publiée par le Guide du concert en 1924 (l'année des Jeux olympiques à Paris) ayant pour objet "La musique et le sport ", un répondant sur cinq affirme qu'il considère que le lien le plus naturel entre la musique et le sport consiste à accompagner les épreuves des athlètes et les matchs. Il est intéressant à ce propos de souligner que le «Divertissement (pendant les jeux et les productions athlétiques) » du Cortège d'athlètes de Vuillemin doit être joué "à la façon d'une musique de scène ".

Le fait d'investir le sport, toutes disciplines confondues, de significations militaires et d'associer à la musique à caractère militaire une fonction sportive reste toutefois une seule des facettes de l'intégration du sport dans la vie des années folles. La musique française des années 1920 (de la chanson à l'opérette, du ballet aux œuvres instrumentales) continue d'intégrer le sport en l'associant à la vie moderne ou à l'érotisme. Par exemple, en même temps que Vuillemin gagnait le concours de Comoedia avec son défilé d'athlètes/soldats, on compose d'autres marches dans la même veine (comme le Défilé des athlètes d'Alphonse Nicot de 1923), mais on retrouve également l'idée que "L'amour est le sport naturel » (c'est un titre tiré de l'« opérette moderne "Flouette, 1924, paroles de J. Marlines, musique de Roger Dumas), ainsi que le personnage d'Hector avec ce qu'il implique - l'ironie sur l'activité physique et les blagues grivoises (voir le « one step chanté » de 1924, Hector fait du sport, paroles de Goudard et Danerty, musique de Pierre Margès).

$\mathrm{Du}$ côté de la musique symphonique et du ballet, on assiste à la naissance d'une musique à programme à sujet sportif qui n'a rien de militaire et qui s'inspire plutôt de la composante cinétique de l'activité physique : tel est le cas des poèmes symphoniques Half-Time (1924) de Bohuslav Martinů, Rugby (1928) d'Arthur Honegger et Le ring (1928) de Filip Lazăr ${ }^{33}$, ainsi que de pièces

32 Cela semble s'être produit tout d'abord par l'initiative des pays fascistes. En mai 1923, quelques mois après l'arrivée de Mussolini au pouvoir, «L'hymne royal italien a été joué à la fin de la rencontre [d'escrime entre le Français Gaudin et l'italien Sassone], alors que La Marseilleise n'a été ni exécutée ni même réclamée par personne " (lettre anonyme du 9 juin 1923, citée dans Arnaud et Riordan 1998, p. 298).

33 Pour la bibliographie au sujet de ces poèmes symphoniques « sportifs », voir Lazzaro 2017. 
comme celles qu'Alexandre Tchérepnine a consacrées à la boxe ( Pour un entraînement de boxe ", 1922, troisième des Trois Pièces pour orchestre de chambre publiées en 1927, et Sonatine sportive pour piano et saxophone, 1939). L'intérêt porté au mouvement est aussi à la base du ballet sur patins à roulettes Skating Rink (1922, argument de Ricciotto Canudo, musique d'Arthur Honegger, chorégraphie de Jean Börlin, décors et costumes de Fernand Léger ${ }^{34}$ ), tandis qu'un autre spectacle des Ballets suédois, Le train bleu de 1924 (scénario de Jean Cocteau, musique de Darius Milhaud, chorégraphie de Bronislava Nijinska, décors d'Henri Laurens et costumes de Coco Chanel) met en scène les sports (natation, tennis, golf) en tant que formes de la vie moderne de la jeunesse insouciante d'après-guerre.

En conclusion, la ridiculisation et la glorification de l'athlète se côtoient tout le long de la période considérée ici. Si la ridiculisation occupe de préférence les espaces voués à la satire sociale, la glorification est présente dans ceux qui sont investis d'une fonction mythopoḯtique (l'école, les fêtes, le stade). La musique, en plus de rendre compte de la perception sociale de l'essor de la culture sportive, participe activement à investir cette dernière d'une signification paramilitaire (surtout durant les premières décennies de la Troisième République, en lien avec la promotion institutionnelle de la gymnastique) et postmilitaire (surtout après la Première Guerre mondiale, au moment où le stade absorbe pacifiquement les fonctions du champ de bataille). Les héros qu'il faut chanter changent et les champs de bataille se transforment, mais les notes qui remplissent les stades confirment aux oreilles qui les écoutent que le sport n'est plus (ou n'a jamais vraiment été) qu'un loisir.

\section{BIBLIOGRAPHIE}

Aderer, Adolphe (1918), "Opéra : Castor et Pollux», Le Temps (23 mars), p. 3.

Andrieu, Gilbert (1988), L'homme et la force. Une histoire de la force à travers des pratiques commercialisées au $X I X^{e}$ et au $X X^{e}$ siècles, Joinville-le-Pont, Actio.

Andrieu, Gilbert (1996), «À propos d'un livre. Pour devenir belle... et le rester, ou La culture physique au féminin avant 1914 ", dans Arnaud et Terret 1996, tome 2, p. 27-39.

Andrieu, Gilbert (1999), La gymnastique au XIXe siècle ou la naissance de l'éducation physique, 1789-1914, Paris, Actio.

Andrieu, Gilbert (2012), "L'éducation du fantassin au début du xxe siècle », dans Robène 2012a, p. 93-102.

Anonyme (1922a), «Inauguration du stade de Saint-Maur », L'Auto (29 mai), p. 4.

Anonyme (1922b), «Inauguration du stade de Saint-Maur », L'Écho de Paris (29 mai), p. 4.

Arnaud, Pierre (1996), "Le genre ou le sexe ? Sport féminin et changement social (XIXe-XXe siècles) », dans Arnaud et Terret 1996, tome 2, p. 147-183.

Arnaud, Pierre (dir.) (1997a), Les athlètes de la République. Gymnastique, sport et idéologie républicaine, 1870-1914, Paris/Montréal, L’Harmattan.

34 Si le sport entre ici dans la salle de spectacle, ce n'est pas sur le plan du sujet (qui est plutôt métaphysique), mais de la fusion entre la danse et une forme d'activité physique récréative (le patinage). Voir Halbreich 1992, p. 573-575 ; Mas 2009. 
Arnaud, Pierre (1997b), «Éducation physique, sport et santé dans la société française. Une France saine et régénérée, 1870-1914 ", dans Arnaud et Terret 1997, p. 89-95.

Arnaud, Pierre, et James Riordan (1998), Sport et relations internationales, 1900-1941. Les démocraties face au fascisme et au nazisme, Paris/Montréal, L'Harmattan.

Arnaud, Pierre, et Thierry Terret (dir.) (1996), Histoire du sport féminin, 2 tomes : « Histoire et identité » et «Sport masculin/sport féminin. Éducation et société », Paris, L'Harmattan.

Arnaud, Pierre, et Thierry Terret (dir.) (1997), Sport, éducation et art, XIXe-XXe siècles, Paris, Éditions du cTHs.

Attali, Michel, et Jean Saint-Martin (dir.) (2010), Dictionnaire culturel du sport, Paris, Armand Colin.

Aviron (1922), «L'inauguration du Stade Saint-Maur », Le Petit Journal (29 mai), p. 4.

Bancel, Nicolas, et Jean-Marc Gayman (2002), Du guerrier à l'athlète. Éléments d'histoire des pratiques corporelles, Paris, Presses universitaires de France.

Bateman, Anthony (dir.) (2015), Sport, Music, Identities, London, Routledge.

Bauer, Thomas (2011), La sportive dans la littérature française des Années folles, Villeneuve d'Ascq, Presses universitaires du Septentrion.

Caillat, Michel (1989), L'idéologie du sport en France depuis 1880. Race, guerre et religion, Paris, Éditions de la Passion/ADAGP.

Callède, Jean-Paul (2000), Les politiques sportives en France. Éléments de sociologie historique, Paris, Économica.

Callède, Jean-Paul (2007), « Maires et ministres entreprenants. L'invention d'une politique des sports (1919-1939) », dans Tétart 2007, p. 155-182.

Caradec, François, et Alain Weill (2007), Le café-concert, $2^{e}$ éd., Paris, Fayard.

Chambat, Pierre (1986), « Les fêtes de la discipline. Gymnastique et politique en France (1879-1914)», dans Pierre Arnaud et Jean Camy (dir.), La naissance du mouvement sportif associatif en France. Sociabilités et formes de pratiques sportives, actes du colloque (Lyon, 5-7 novembre 1985), Lyon, PUL, p. 87-96.

Chambat, Pierre (1997), «Les vitrines de la République. Uniformes, défilés, drapeaux dans les fêtes de gymnastique en France (1879-1914) ", dans Arnaud 1997a, p. 259-268.

Charpentier, Raymond (1922), "L'art et les sports. Concours de musique », Comoedia, no 3355 (21 février), p. 1-2.

Chéron, Adolphe, «L'art et l'athlétisme au stade », Comoedia, n 3340 (6 février), p. 1.

Clastres, Patrick, et Paul Dietschy (2006), Sport, culture et société en France du XIX siècle à nos jours, Paris, Hachette.

Clavel, Cyrille (2014), Saint-Maur, cité des sports. Regards sur trois siècles de sport saint-maurien, Saint-Maur-des-Fossés, Le Vieux Saint-Maur.

Cocteau, Jean ([1924]2003), Le train bleu, dans Théatre complet, Paris, Gallimard, p. 55-61.

Comoedia (1922), «L'art et les sports », Comoedia, no 3347 (13 février), p. 1.

Coubertin, Pierre de ([1912]1992), "Le sport et la guerre », La Revue olympique (avril) ; repris dans idem (1913), Essais de psychologie sportive, Paris, Payot ; éd. moderne Grenoble, Millon, 1992, p. 194-198.

Daniel, Laurent (dir.) (2009), L'art et le sport, actes du XII colloque international du Comité européen pour l'histoire des sports (Lorient, 2007), Biarritz, Atlantica.

Dalisson, Rémi (2009), Célébrer la nation. Les fêtes nationales en France de 1789 à nos jours, Paris, Nouveau monde.

Davis, Mary E. (1999), "Modernity à la Mode. Popular Culture and Avant-Gardism in Erik Satie's Sports et divertissements ", The Musical Quarterly, vol. 83, n 3, p. 430-473.

Defrance, Jacques (2007), " Le sport français dans "l'entre-deux-guerres" », dans Tétart 2007, p. 79-105. 
Delaplace, Jean-Michel (1996), « Conceptions de l'éducation physique féminine en France entre les deux guerres. Vers une gymnastique gynécologique? », dans Arnaud et Terret 1996, tome 2, p. 69-79.

Dietschy, Paul (2007), «Le sport et la Première Guerre mondiale », dans Tétart 2007, p. 57-77.

Docx, Guillaume, H. Patigny, et Charles Miry (1881), Recueil de chants d'écoles. Chants scolaires, chants gymnastiques, chants pour jeux, Namur, Wesmael-Charlier.

Francfort, Didier (2014), « Musiques militaires », dans Florence Gétreau (dir.), Entendre la guerre. Sons, musiques et silence en 14-18, Paris, Gallimard/Péronne, Historial de la Grande Guerre, p. 24-35.

Froissart, Tony (2010), « Gymnastique », dans Attali et Saint-Martin 2010, p. 63-67.

Gibbons, William (2013), Building the Operatic Museum. Eighteenth-Century Opera in Fin-de-Siècle Paris, Rochester, University of Rochester Press.

Gleyse, Jacques (1996), "L'image de la femme dans les discours sur l'eP et le sport de 1870 à 1930. Un "fait social total" ? ", dans Arnaud et Terret 1996, tome 2, p. 41-57.

Gutsche-Miller, Sarah (2015), Parisian Music-Hall Ballet, 1871-1913, Rochester, University of Rochester Press.

Halbreich, Harry (1992), Arthur Honegger, un musicien dans la cité des hommes, Paris, Fayard/Sacem.

Hill, Jeffrey (2009), "War, Remembrance and Sport. Abide with Me and the FA Cup Final in the 1920s », dans Anthony Bateman et John Bale (dir.), Sportings Sounds. Relationships Between Sport and Music, London, Routledge, p. 164-178.

Holt, Richard (1991), "Women, Men and Sport in France, c. 1870-1914. An Introductory Survey », Journal of Sport History, vol. 18, $\mathrm{n}^{\circ}$ 1, p. 121-134.

Interim (1918), «Théâtre national de l'Opéra. Castor et Pollux de Rameau », L'Écho de Paris (23 mars), p. 2.

Janin, Jacques (1929), «La musique américaine devant l'Occident », Le Courrier musical, vol. 31, nº 4 (15 février), p. 93-94. Consultable dans la banque de données du PHEM : http://lmhsbd.oicrm.org/ media/ART-JAJ-1929-01.pdf (consulté le 23 octobre 2017).

Jobert, Timothée (2006), "Les combattants "nègres" de Paris. Comparaison franco-américaine de l'attitude des "blancs" à l'égard des pugilistes "noirs" durant la Belle Époque (1907-1914) ", STAPS, vol. 71, nº 1, p. 23-36.

Laplagne, Jean-Paul (1996), " La femme et la bicyclette à l'affiche », dans Arnaud et Terret 1996, t. 1, p. 83-94.

Laty, Dominique (1996), Histoire de la gymnastique en Europe de l'Antiquité à nos jours, Paris, Presses universitaires de France.

Lazzaro, Federico (2014a), "L'artiste, le soldat et l'athlète. Musique de guerre, musique de sport ", communication dans le panel Musique et musicologie en France lors du colloque international Grande Guerre et paix, Music and War from Napoleon to the WW1, Lucques, 28-30 novembre.

Lazzaro, Federico (2014b), "L'esprit du corps. Musique et sport à Paris dans les années 1920 », communication au concours de conférences Présences de la musique 2014 (Société québécoise de recherche en musique), Montréal, 23 avril. Enregistrement disponible en ligne : https://youtu.be/ wJleQ9Znhsg (consulté le 23 octobre 2017).

Lazzaro, Federico (2015-2016), «Body's Soul. Music and Sport in Interwar Paris / L'esprit du corps. Musique et sport à Paris dans les années 1920 », conférence donnée dans le cadre des séries Music Research Talks Series - Fifth Gala Season, Montréal, Concordia University, 27 novembre 2015, et Présences de la musique 2015 (Société québécoise de recherche en musique), Université du Québec à Montréal, 17 février 2016.

Lazzaro, Federico (2017), " Le son du sport, ou L'orchestre-stade de Martinů, Honegger et Lajtha », Euterpe, $\mathrm{n}^{\circ} 29$ (juillet) : « Le son orchestral de 1918 à 1955 », p. 31-39.

Leteuré, Stéphane (2014), Camille Saint-Saëns et le politique de 1870 à 1921. Le drapeau et la lyre, Paris, Vrin. 
Liotard, Philippe (1996), «L'impossible spécificité de l'éducation physique féminine », dans Arnaud et Terret 1996, tome 2, p. 185-211.

Mas, Josiane (2009), « Skating Rink. Une musique cinétique fidèle à l'intention unanimiste et symbolique du poème de Ricciotto Canudo ", dans Peter Jost (dir.), Arthur Honegger. Werk und Rezeption/L'euvre et sa réception, Bern, Peter Lang, p. 275-289.

Montorgueil, Georges (1897), La parisienne peinte par elle-même, Paris, L. Conquet. Disponible sur Gallica : http://gallica.bnf.fr/ark:/12148/bpt6k123293b (consulté le 23 octobre 2017).

Nannestad, Ian (2015), «Bubbles, Abe My Boy, and The Fowler War Cry. Singing at the Vetch Field in the 1920s ", in Bateman 2015, p. 28-37.

Perrin, Édouard (1908), "Castor et Pollux à Montpellier ", Bulletin français de la Société internationale de musique (section de Paris) ancien Mercure musical, vol. 4, n 2 (15 février), p. 103-106.

Prost, Antoine (1977), Les anciens combattants et la société française, 1914-1939, 3 vol., Paris, Presses de la Fondation nationale des sciences politiques.

Prost, Antoine ([1977]2014), Les anciens combattants, 1914-1940, 2e éd., Paris, Gallimard.

Prost, Antoine ([1984]1997), «Les monuments aux morts. Culte républicain ? Culte civique ? Culte patriotique?", dans Pierre Nora (dir.), Les lieux de mémoire, $2^{e}$ éd. en 3 vol., Paris, Gallimard, vol. 1, p. 199-223.

Rameau, Jean-Philippe (2002), Castor et Pollux, numéro spécial de L'Avant-Scène Opéra, no 209.

Rameau, Jean-Philippe (2013), Castor et Pollux, livret (1737) en français modernisé, Centre de musique baroque de Versailles/Philidor.

René-Jean (1922), «L'art et les sports. Concours de sculpture », Comœedia, no 3351 (17 février), p. 1.

Rennes, Juliette (2013), Femmes en métiers d'hommes. Cartes postales, 1890-1930, Saint-Pourçain-sur-Sioule.

Robène, Luc (1996), "Vers la création d'un sport féminin. Des filles de l'air aux aéronautes ", dans Arnaud et Terret 1996, tome 1, p. 165-184.

Robène, Luc (2010), « Guerre », dans Attali et Saint-Martin 2010, p. 311-312.

Robène, Luc (dir.) (2012a), Le sport et la guerre, XIXe et XX siècles, Rennes, Presses universitaires de Rennes.

Robène, Luc (dir.) (2012b), « Sport et guerre (XIX et $\mathrm{Xx}^{\mathrm{e}}$ siècles). Un nouvel objet d'histoire ? ", dans Robène 2012a, p. 7-21.

Robert, Alfred (1924), Au soleil du stade, Paris, Élaia.

Russell, David (2015), " "See, the Conquering Hero Comes! Sound the Trumpets, Beat the Drums". Music and Sport in England (1880-1939)», dans Bateman 2015, p. 11-27.

Saint-Martin, Jean (2007), "Sport, nationalisme et propagande (1918-1939) », dans Tétart 2007, p. 183-208.

Saint-Martin, Jean (2006), « Philippe Tissié ou l'éducation physique au secours de la dégénérescence de la jeunesse française (1888-1935) ", Revue d'histoire de l'enfance "irrégulière ", no 8 (15 novembre) : «Le corps du délinquant», p. 119-132.

Salomon, Hélène (1996), «Le corset, entre la beauté et la santé », dans Arnaud et Terret 1996, tome 2, p. 11-26.

Stewart, Mary Lynn (2001), For Health and Beauty. Physical Culture for Frenchwomen, 1880s-1930s, Baltimore, Johns Hopkins University Press.

Terret, Thierry (1997), « Le son du corps. Gymnastique et chant à la fin du XIX siècle ", dans Arnaud et Terret 1997, p. 47-73.

Terret, Thierry (2003), Les Jeux interalliés de 1919. Sports, guerre et relations internationales, Paris, L'Harmattan.

Terret, Thierry (2007), « Sport et genre (1870-1945)», dans Tétart 2007, p. 355-376. 
Tétart, Philippe (dir.) (2007), Histoire du sport en France, 2 vol., vol. 1 : « Du Second Empire au régime de Vichy ", Paris, Vuibert/Musée national du sport.

Tétart, Philippe (2016), "Musique, sports et divertissements », épisode de l'émission radiophonique par Karine Le Bail, Un air d'histoire, France Musique (6 novembre), www.francemusique.fr/ emissions/un-air-d-histoire/musique-sport-et-divertissements-par-philippe-tetart-29662 (consulté le 23 octobre 2017).

Tiersot, Julien (1920), "Souvenirs de cinq années (1914-1919) », Le Ménestrel, vol. 82, n 3/4368 (16 janvier), p. 24-26.

Tissié, Philippe (1919), L'éducation physique et la race. Santé - travail - longévité, Paris, Flammarion.

Turcot, Laurent (2016), Sports et loisirs. Une histoire des origines à nos jours, Paris, Gallimard/Folio histoire.

Ulmann, Jacques (1977), De la gymnastique aux sports modernes. Histoire des doctrines de l'éducation, Paris, Vrin.

Valmy-Baysse, J. (1922), «L'art et les sports. Concours de poésie », Comøedia, n 3357 (23 février), p. 1.

Vuillemin, Louis (1922), Cortège d'athlètes, op. 24, partition pour piano conducteur, Nantes, Jacques Vuillemin.

Watkins, Glenn (2003), Proof Through the Night. Music and the Great War, Berkeley/Los Angeles, University of California Press. 